Original Research Article

\title{
Assessment of prescription pattern using WHO drug prescribing indicators in medicine wards of a tertiary care teaching hospital: a retrospective observational study
}

\author{
Narendra P. Bachewar, Sachin R. Choudhari*, Sujata Dudhgaonkar
}

Department of Pharmacology, Shri Vasantrao Naik

Government Medical College, Yavatmal, Maharashtra, India

Received: 17 June 2017

Accepted: 10 July 2017

*Correspondence to: Dr. Sachin R. Choudhari, Email: sachinchoudhari06@ gmail.com

Copyright: (C) the author(s), publisher and licensee Medip Academy. This is an openaccess article distributed under the terms of the Creative Commons Attribution NonCommercial License, which permits unrestricted noncommercial use, distribution, and reproduction in any medium, provided the original work is properly cited.

\begin{abstract}
Background: Rational prescribing is an essential skill for every prescriber. However many times it seems a difficult task for various reasons. Such practices ultimately increase the mortality, morbidity and financial burden on the patient. Hence, we aimed our study to evaluate appropriateness of prescription pattern according to WHO drug prescribing indicators, few complementary indicators and classify prescription errors.

Methods: A retrospective observational study, conducted in medical record section of tertiary care teaching hospital of Maharashtra during the period of 6 months. Total 400 randomly selected prescriptions from Medicine inpatient wards were scrutinized.

Results: Average number of drugs per prescription was 5.20 trending towards polypharmacy. Drugs prescribed by generic name were $13.88 \%$, injectable drugs were part of $93.50 \%$ prescriptions, $78.25 \%$ prescriptions contained an antimicrobial agent and Percentage of drugs prescribed from NELM 2011 was $72.36 \%$. Illegible handwriting in $68 \%$ cases was the important cause of prescription errors. These errors found in $73 \%$ of prescriptions.

Conclusions: The present study showed that the practices were trending towards irrational prescribing. Polypharmacy and illegible prescriptions were dominated. Regular prescription audit will help to rectify such practices. Also, there is an urgent need of sensitization of prescriber through new treatment guidelines, seminar, presentations and discussions on regular basis.
\end{abstract}

Keywords: Polypharmacy, Prescription audit, Prescription error, Rational prescribing, Ronald Neville

\section{INTRODUCTION}

Rational prescribing is an essential skill, which needs to be improved by every prescriber. It not only shows the physicians' knowledge but also his attitude towards appropriate drug prescribing. ${ }^{1}$ However at times it seems a difficult task due to larger patient load and availability of variety of pharmaceutical formulations, particularly in developing countries like India. More than 50\% medicines are dispensed inappropriately, while $50 \%$ of patients fail to receive medicines correctly and around one third of world population is not able to receive essential medicines because of various reasons. ${ }^{2}$ This situation is even worse for developing countries.

Irrational prescriptions unnecessarily increase the cost and duration of treatment. Such practices also lead to emergence of drug interactions, drug resistance and adverse drug reactions. It ultimately increases the mortality, morbidity and financial burden on the patient. ${ }^{1}$

In a previous research Satish Kumar BP et al, showed that the mean number of drugs per prescription was 6.66 with a range between 3 to 15 drugs. The majority $(67.32 \%)$ of 
prescriptions were prescribed with more than 5 drugs. The brand prescribing dominated $(60.91 \%)$ the generic prescribing (39.09\%). The prescriptions containing AMAs were $57.07 \%$. Majority $(71.03 \%)$ of the drugs were from National List of Essential Medicine of India 2011. ${ }^{3}$

In similar study Binit et al, also showed that drug prescribed by generic and brand name were $48.79 \%$ and $51.21 \%$, parenteral formulations and fixed dose combinations (FDCs) were prescribed in $25.60 \%$ and $17.87 \%$ of patients respectively, $48.79 \%$ and $44.44 \%$ drugs were prescribed from National and WHO essential medicine list respectively, average number of drugs per prescription patient was 9.37 (95\% CI: 9.09-9.64). ${ }^{4}$

In order to decrease this irrationality, rational prescribing skills of clinicians need to be improved by regular prescription audits and sensitizing the prescribers about rational prescribing practices. Hence this research is planned to analyze prescription pattern and its appropriateness according to WHO drug prescribing indicators, 1993. The periodic assessment of drug use pattern will help to identify these problems and hence to promote rational drug use. ${ }^{5}$ Our objectives for the study were:

- To analyze prescription pattern in medicine ward, using WHO drug prescribing indicators.

- To find out prescription errors, using Ronald G. Neville Criteria, 1989.

\section{METHODS}

This was a retrospective observational study, conducted in medical record section of our tertiary care teaching hospital. To carry out this research we used following categories of indicators as part of our observations.

WHO drug prescribing indicators as outlined below:

- Mean/Average number of drugs prescribed.

- $\quad$ Percentage of drugs prescribed by generic name.

- Percentage of prescriptions containing AMAs.

- Percentage of prescriptions containing injectables.

- Percentage of drugs prescribed from the national EDL.

Complimentary indicators as outlined below:

- $\quad$ Illegible Handwriting

- $\quad$ Number of Fixed Drug Combination approved by WHO and National Essential Drug List

- Number of drugs from National Essential Drug List

- Number of improper Dose, Duration, Frequency

- Use of more than one drug from same class

- Use of any contraindicated drug

In addition to the indicators mentioned above, we also used following classification of prescription errors. Neville et al designed prescription error classification in 1989, as follows. ${ }^{6}$

1. Type A error which is potentially serious. These prescriptions pose hazard to the health of patients if dispensed. For example, if dose of cardiac drugs changed by factor 10 or its unit changed from milligram to gram can create a significant health issues. Similarly if there is a confusion of handwriting between chlorpropamide and chlorpromazine. Use of contraindicated medicines.

2. Type B error in which pharmacist has to contact relevant prescriber to dispense the medicine. These prescriptions need to be confirmed by prescriber before dispensing. It includes completely illegible handwriting, fails to write dosage form of drugs such as phenytoin.

3. Type $\mathrm{C}$ error in which pharmacist uses his own decision before dispensing the medicine without been contacting to prescriber. For example wrong pack size of AMAs or skin medicines.

4. Type D error said to be trivial that is of little worth or importance and it mainly involve poor handwriting and spelling mistakes, which do not pose health hazard. These errors can be easily avoided.

Authors scrutinized randomly selected 400 prescriptions during the period of $1^{\text {st }}$ July 2016 to $31^{\text {st }}$ December 2016. We selected all the prescriptions of the patients, up to the age of 70 years, of any gender, admitted to medicine ward. We did not include Medico legal cases and incomplete medical records in our study.

Written permission from the Institutional ethics committee was taken prior to start of the study. Complete confidentiality of data was maintained throughout the research.

\section{Study statistics}

Sample size of the study is as per the guidelines given by WHO for prescription auditing at any hospital set up. ${ }^{7}$ Microsoft office (excel) ver. 2010, Graph pad prism ver. 5.01, SPSS ver. 16 was used for collecting, storing and analyzing data.

\section{RESULTS}

During the study period total 400 prescriptions were evaluated. The Result of core WHO drug prescribing indicators were as shown in the Table 1.

\section{Average number of drugs per prescription}

Number of drugs per prescription is an important index to evaluate Polypharmacy. Polypharmacy is defined as the concomitant use of five or more drugs. For inpatient average number of drugs per prescription ranges from 4-6. Our study showed that average number of drugs per 
prescription was 5.20 which range from 2-15 drugs (Figure $1)$.

Table 1: WHO drug prescribing indicators.

\begin{tabular}{|ll|}
\hline Parameters & Values obtained \\
\hline $\begin{array}{l}\text { Average number of drugs per } \\
\text { prescription }\end{array}$ & 5.20 \\
\hline $\begin{array}{l}\text { Percentage of drugs prescribed by } \\
\text { generic name }\end{array}$ & $13.88 \%$ \\
\hline $\begin{array}{l}\text { Percentage of prescription with } \\
\text { injectable drugs }\end{array}$ & $93.50 \%$ \\
\hline $\begin{array}{l}\text { Percentage of prescription with an } \\
\text { antimicrobial agent prescribed }\end{array}$ & $78.25 \%$ \\
\hline $\begin{array}{l}\text { Percentage of drugs prescribed } \\
\text { from NELM 2011 }\end{array}$ & $72.36 \%$ \\
\hline
\end{tabular}

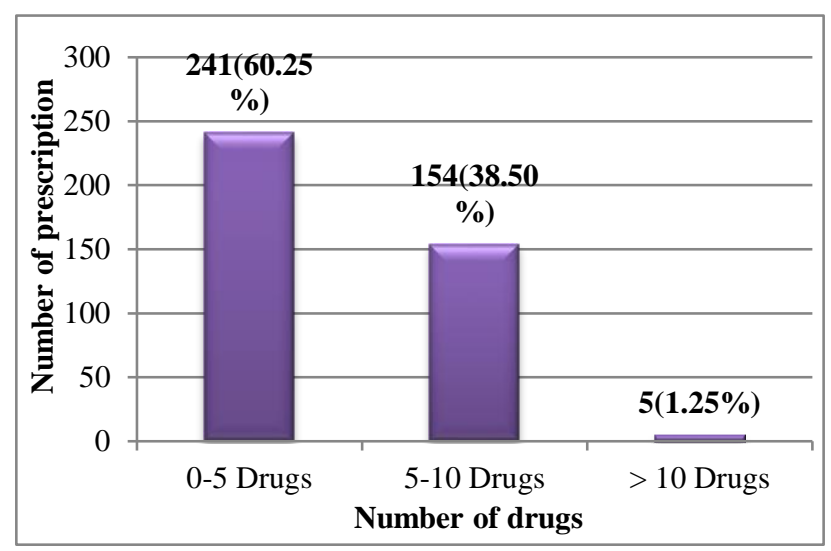

Figure 1: Number of drugs per prescription.

\section{Percentage of drugs prescribed by generic name}

Our study showed that brand (proprietary) name dominated generic name while writing the prescription. Out of total 2081 drugs prescribed $86.12 \%$ were written in brand name and $13.88 \%$ were that of generic. Figure 2 clearly shows dominance of brand name over generic name. Further analyses of percentage of prescription with generic drugs were shown in the Table 2. Out of total 400 prescriptions, 58\% (232) of prescriptions were not contained single drug written in generic name.

Table 2: Percentage of prescription with generic name.

\begin{tabular}{|lll|}
\hline $\begin{array}{l}\text { Number of } \\
\text { drugs }\end{array}$ & $\begin{array}{l}\text { Number of } \\
\text { prescription }\end{array}$ & \% of prescription \\
\hline 0 & 232 & 58.00 \\
\hline 1 & 83 & 20.75 \\
\hline 2 & 54 & 13.50 \\
\hline 3 & 26 & 06.50 \\
\hline 4 & 05 & 01.25 \\
\hline
\end{tabular}

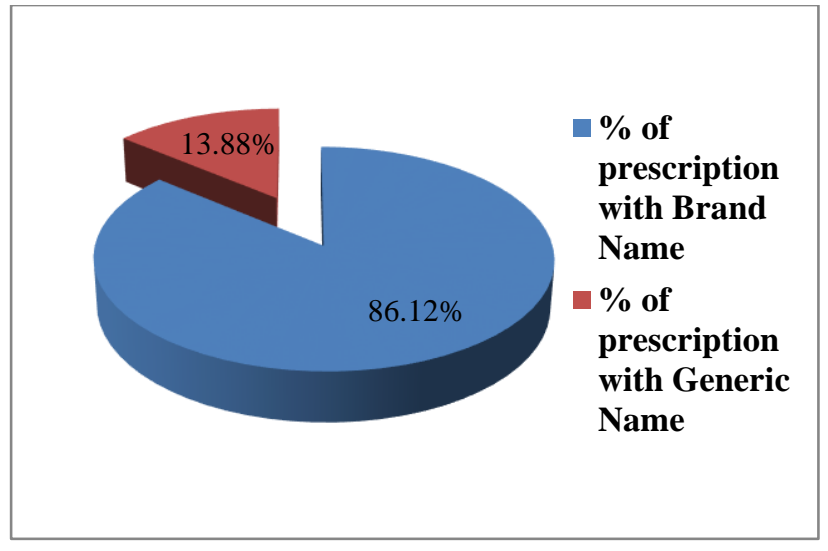

Figure 2: Percentage of drugs prescribed by generic name versus brand name.

\section{Percentage of prescription with injectable drugs}

In our study, 93.5\% (374) prescriptions were containing injectable drugs. $6.5 \%$ (26) of prescriptions were found to be prescribed with no injectable drugs. Further analysis of injectable drugs is shown in the Table 3.

Table 3: Percentage of prescription with injectable drugs.

\begin{tabular}{|lll|}
\hline $\begin{array}{l}\text { Number of } \\
\text { injectable drugs }\end{array}$ & $\begin{array}{l}\text { Number of } \\
\text { prescriptions }\end{array}$ & $\begin{array}{l}\% \text { of } \\
\text { prescriptions }\end{array}$ \\
\hline $00-03$ & 247 & 61.75 \\
\hline $03-06$ & 143 & 35.75 \\
\hline $06-09$ & 09 & 02.25 \\
\hline $09-12$ & 01 & 00.25 \\
\hline$>12$ & 00 & 00 \\
\hline
\end{tabular}

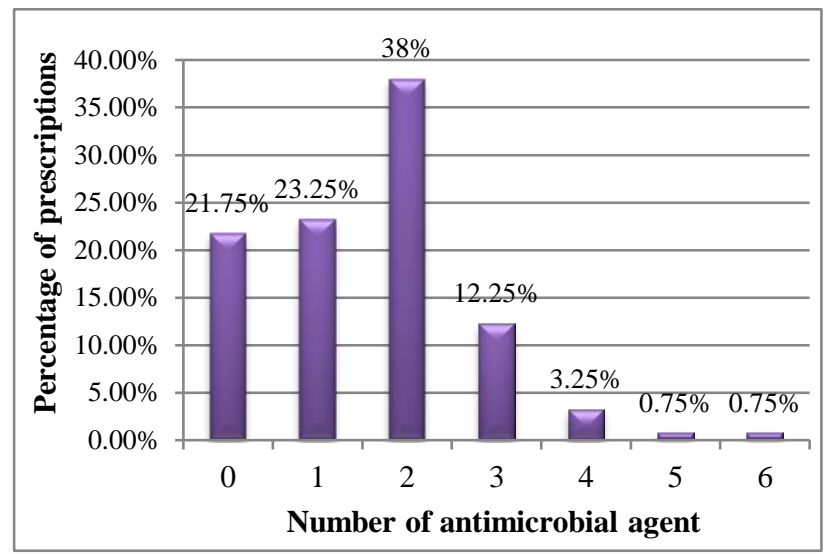

Figure 3: Percentage of prescription with Antimicrobial agents (AMA).

\section{Percentage of prescription with an antimicrobial agent prescribed}

As shown in Figure 3, around 21.75\% (87) prescriptions were found to be not containing a single antimicrobial 
agent (AMA). Many prescriptions contained $3(12.25 \%)$ or $4(3.25 \%)$ AMAs.

Percentage of drugs from National essential list of medicine, 2011 (NELM)

Out of total 2081 drugs prescribed $72.36 \%$ (1506) drugs were from national essential list of medicine. Percentage of prescription with number of generic drugs was shown in the Table 4.

Table 4: Percentage of prescription with drugs from NELM.

\begin{tabular}{|lll|}
\hline $\begin{array}{l}\text { Number of drugs } \\
\text { from NELM }\end{array}$ & $\begin{array}{l}\text { Number of } \\
\text { prescription }\end{array}$ & $\begin{array}{l}\text { \% of } \\
\text { prescription }\end{array}$ \\
\hline $00-02$ & 78 & 19.50 \\
\hline $02-04$ & 209 & 52.25 \\
\hline $04-06$ & 96 & 24.00 \\
\hline $06-08$ & 15 & 03.75 \\
\hline $08-10$ & 02 & 00.50 \\
\hline$>10$ & 00 & 00 \\
\hline
\end{tabular}

NELM - National essential list of medicine, 2011

We also analyzed few complimentary indicators as follows:

\section{Bad / Illegible handwriting}

In our study, 68\% (273) of prescriptions were present with illegible handwriting and that of $32 \%$ (128) with legible handwriting (Figure 4).

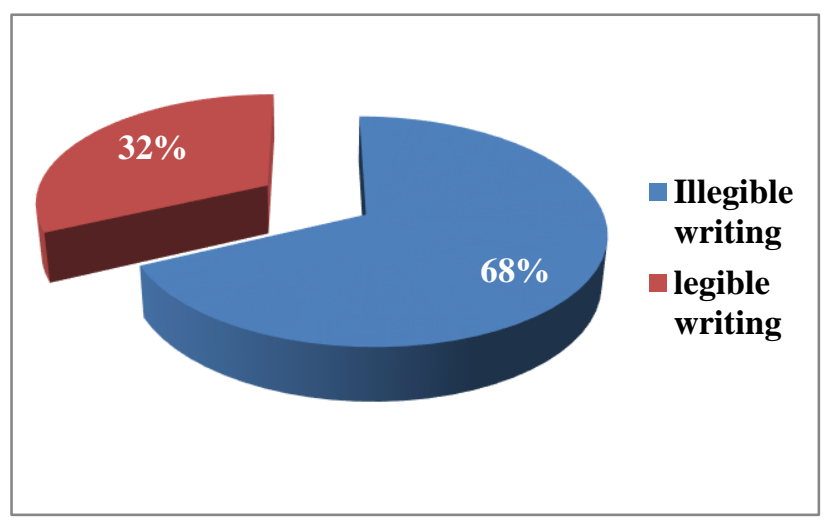

Figure 4: Percentage of prescriptions with illegible writing.

\section{Percentage of prescription with not approved FDCs}

Out of total 400 prescriptions, 4\% (16) of prescriptions were containing fixed drug combinations (FDCs) which are not approved by World Health Organization.

\section{Number of drugs from similar class}

Many prescriptions were containing drugs from similar class e.g. antacids, analgesics and antimalarial drugs. In our study, $12 \%$ (48) of prescriptions contained drugs from similar class (Figure 5).

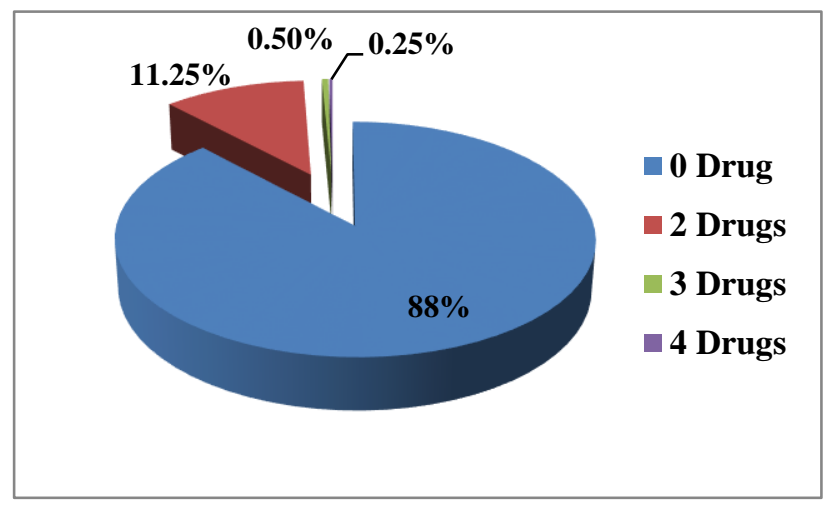

Figure 5: Percentage of prescription with drugs from similar class.

\section{Improper Dose, Duration and frequency $(\mathrm{DDF})$}

In our study we found that, majority of prescriptions i.e. $68.25 \%$ (273) were present with proper dose, duration and frequency. Number of prescription with improper DDF were around $31.75 \%$ (127). The results were cumulative of all three parameters (Figure 6).

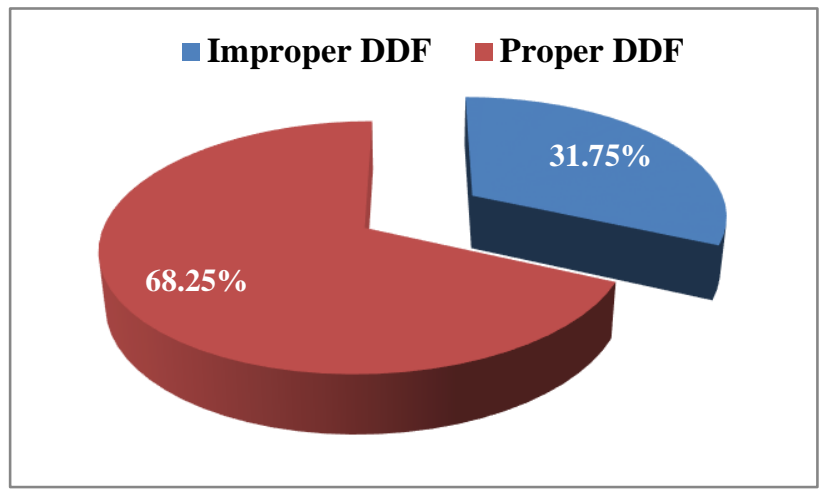

Figure 6: Percentage of prescription with improper DDF.

\section{Prescriptions containing contraindicated medicines}

While evaluating the prescriptions, we also came to know that $3.50 \%$ (14) prescriptions were having contraindicated medicines.

These were the results of complimentary indicators. We also evaluated impact of irrational prescribing with the help of two parameters. First duration of hospital stay and second treatment outcome. Results of these parameters were as follows;

\section{Duration of hospital stay}

One of the important impacts of irrational prescribing is increased days of hospitalization. So while evaluating, we 
found that $80 \%$ (320) of patients were admitted for $0-5$ days, whereas $16.75 \%$ (67) of patients were having 5-10 days of hospitalization (Figure 7).

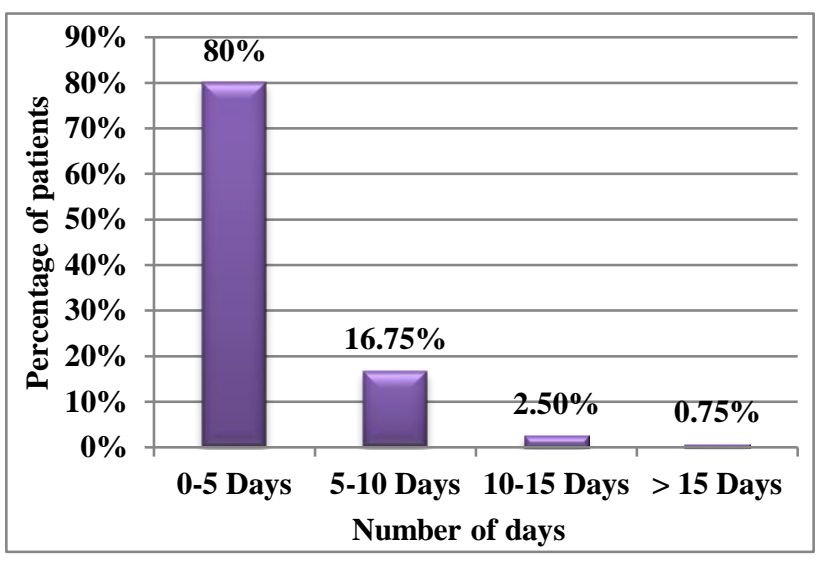

Figure 7: Duration of hospital stay.

\section{Treatment outcome}

Out of 400 patients, majority i.e. 80.75\% (323) patients were discharged. Further analysis shown in the (Figure 8).

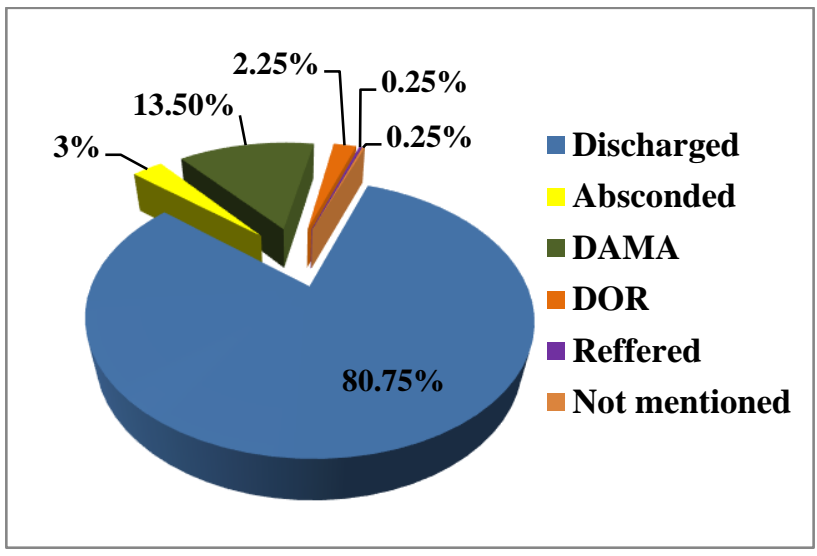

DAMA- Discharged against medical advice DOR - Discharged on request

Figure 8: Treatment outcome.

Table 5: Prescription error classification $(n=400)$.

\begin{tabular}{|lll|}
\hline $\begin{array}{l}\text { Error } \\
\text { classification }\end{array}$ & $\begin{array}{l}\text { Number of } \\
\text { prescription }\end{array}$ & $\begin{array}{l}\text { \% of } \\
\text { prescription }\end{array}$ \\
\hline Type A & 13 & 03.25 \\
\hline Type B & 12 & 03.00 \\
\hline Type C & 96 & 24.00 \\
\hline Type D & 171 & 42.75 \\
\hline No error & 108 & 27.00 \\
\hline
\end{tabular}

With the help of Ronal Neville G criteria, we also found out prescription errors. These errors were divided into four categories according to its severity impact into Type A, B, C and type D. As shown in the Table 5, class D type of errors contributed maximum to the prescription errors.
Some prescriptions were also contained very hazardous type A error.

\section{DISCUSSION}

Drug prescribing is an important art which communicates between health care provider and patient. It represents the prescriber's attitude towards health care in terms of treatment. A rational prescribing is one of the key factors for the disease being treated. It is also important in terms of treatment outcome and prevention of drug resistance. Since, indiscriminate or misuse or overuse of drugs (specifically AMAs) leads to drug resistance and ultimately treatment failure. To prevent this and to promote rational prescribing WHO has provided few drug prescribing indicators. These indicators would help us to understand prescription pattern, to know errors in prescriptions and to find out various ways to rectify them.

In our study, we analysed prescription pattern of medicine ward, using WHO drug prescribing indicators. We also analysed it for complimentary indicators, which we came to know while formulating our study. List of complimentary indicators varies and it mainly depends upon prescribing practices at the local level.

We used the Ronald G. Neville classification of errors to conduct our research. According to Ronald G. Neville, these prescription errors can be classified into type A, B, $\mathrm{C}$ and D according to its effect on the patient health care. ${ }^{6}$ Type A error supposed to be lethal whereas type D error was mild and can be easily avoided.

\section{WHO Indicators}

Average number of drugs per prescription is an important parameter to identify poly pharmacy. ${ }^{8}$ In our study we found that Average number of drugs per prescription was around 5.20, but more importantly range of these drugs was from 2-15. This indiscriminate use of drugs leads to adverse drug reaction, drug-drug interaction, and increased cost of therapy, increased hospital stay and non compliance due to pill burdon. This value is similar to the study conducted by Pathak et al, and Meena et al, i.e. 5.11 and 5.12 respectively but at the same lower than the study done by Satish kumar BP et al which was around $6.66 .^{3,9,10}$

Polyparmacy practices should be discouraged in order to increase patient compliance, to reduce the chances of treatment failure and to avoid possible drug interactions.

According to WHO standards, every drug must be prescribed with generic name. This is to avoid confusion between different classes of drugs with near about similar brand names while dispensing and also to decrease the cost of therapy. In this study, brand name dominated generic name while writing the prescription. Out of total 2081 drugs prescribed $86.12 \%$ (1792) drugs were written in brand name and $13.88 \%$ (289) drugs were that of generic 
name. These results were significantly lower than the studies conducted at other hospitals by Satish kumar et al, and Pathak et al, which showed generic prescribing was around $38.33 \%$ and $89.88 \%$ respectively. ${ }^{3,9}$ The value is higher than study conducted by Meena et al, which was around $3.64 \%$ but still it is much lower than WHO standards which is $100 \% .{ }^{10}$ Also,_recently according to new amendment by medical council of India use of generic drug while prescribing made it compulsory. ${ }^{11}$ Generic prescribing would help to rationalize the use of available drugs and reduce the cost of treatment.

Prevalence of AMA use is increasing as organisms are resistant to previously sensitive AMA. Judicious use of AMAs is necessary to prevent this emergence of drug resistant. We found, $21.75 \%$ (87) prescriptions were not containing any AMA. At the same time, many prescriptions were contained 2 (38\%), 3 (12.25\%), 4 $(3.25 \%), 5(0.75 \%)$ and $6(0.75 \%)$ antimicrobial agents. In total, $78.25 \%$ (313) prescriptions were contained one or more antimicrobial agent. These values were much higher when we compared with the study done by Satish Kumar BP et al, Meena et al, and Pathak et al, study which showed $57.07 \%, 57.73 \%$ and $24.27 \%$ respectively. ${ }^{3,9,10}$ More than two third of AMAs prescribed were Cotrimoxazole, cephalosporin and penicillin group. These observations were similar to the study done by Gopalakrishnan, et al in private sector. ${ }^{12}$ There are many national guidelines for the use of AMAs through various national health policies and/or programs. ${ }^{13}$ Main aim of all these national programs is to prevent emergence of drug resistant through appropriate use of AMAs.

Now days, prescriptions with more number of injectables have been reported in various studies conducted by different authors. In this study about, 6.5\% (26) of prescriptions were found to be prescribed with no injectable drugs whereas $93.5 \%$ (374) prescriptions were containing injectable drugs. Similar study by Satishkumar et al, Meena et al, and Pathak et al, showed percentage of prescription with at injectable drug was around 69.26\%, $59.1 \%$ and $24.05 \%$ respectively. ${ }^{3,9,10} \mathrm{We}$ found that these values were much lower than the present study. Point of concern regarding with injection is safety. Since many diseases like HIV, HBsAg, Hepatitis C can be transferred through it if proper safety precautions were not taken. ${ }^{14} \mathrm{It}$ also increases burden on biomedical waste. We also opine that giving medicines by injectable route is one of the indications of in-house treatment of patients.

Every country has a list of essential medicine which mainly depends upon need of population, India also has national essential list of medicine which to be followed by every government hospital. The list is updated time to time in response to changing disease pattern and need of new drugs. The WHO defined essential medicines as, "Those that satisfy the priority healthcare needs of the population". 15 They are selected according to need of population, data on safety and efficacy of the particular drug and cost. These drugs need be present at all times, must be in a different dosage form, in adequate amount and at an affordable price. We found, out of total 2081 drugs prescribed $72.36 \%$ (1506) drugs were from national essential list of medicine. The results were similar to study conducted by Satish kumar et al, and Pathak et al, i.e. 71.03 and $76.06 \%$ but it was higher than study done by Meena et al, $45.50 \% .^{3,9,10}$

\section{Complimentary indicators}

A legible handwriting while prescribing the drugs means it should be understandable by everyone while dispensing the drugs. It mainly avoids confusion between nursing staff or patient's relative while dispensing the medicines. In this study, 68\% (273) of prescriptions were present with illegible handwriting and that of $32 \%$ (128) with legible handwriting. This is mainly because of heavy patient load at government hospitals. This illegible handwriting leads to serious consequences if wrong drugs are dispensed by the paramedical staff. To avoid this, a prescriber can habituate himself of writing in all capital letters.

In our $18^{\text {th }}$ national essential list of medicine, around 26 fixed drug combinations (FDCs) are present which were approved by WHO. In our study, out of total 400 prescriptions, 4\% (16) of prescription were containing FDCs which are not approved by World Health Organization. In the study conducted by Narayan et al showed most of post graduate students were unaware of the WHO-EML and total number of FDCs included in it. Specifically, they did not know about banned FDCs. There was serious lack of knowledge about their (FDCs) advantage and disadvantages and they need urgent sensitization about it. ${ }^{16}$

In our study many prescriptions were containing drugs from similar class viz. antacids, analgesics, and antimalarial drugs treatment. We found $12 \%$ (48) of prescriptions were containing drugs from similar class. Co prescription of similar drugs from similar group does not add to any extra advantage over single drug therapy. Rather it increases the cost of treatment. It leads to wastage of medicines and decreases patient's compliance. Especially in government hospitals where stock of medicine is very much limited it can create different problem. The study from Indonesia describes, patients exposed to unnecessary drug therapy experienced more adverse effect than its positive effects. ${ }^{17}$

Dose, duration and frequency are the important parameters while prescribing the drugs. It forms the integral part of rational pharmacotherapy. Since, under dosing will not show any therapeutic effect and excess dose will lead to toxicity. Same is with the frequency and duration. In our study we found that, majority of prescriptions i.e. $68.25 \%$ (273) were present with proper dose, duration and frequency. Number of prescription with improper DDF was around $31.75 \%$ (127). The results were cumulative of all three parameters. Being a tertiary care hospital this 
number indicates there is urgent need of sensitization about it among prescribers.

Prescription with contraindicated medicine: While evaluating the prescriptions, we also came to know that $3.50 \%$ (14) prescriptions were having contraindicated medicines. E.g. a drug pentazocine which is an opiod analgesic is contraindicated in acute myocardial infarction. ${ }^{18}$ Also simultaneous administration of ciprofloxacin with antacids decreases its absorption; iron tablets administered with antacids decreases its absorption, since iron needs acidic environment. Such contraindicated medicines were encountered.

To see the impact of irrational prescribing, we considered two important parameters. First one is treatment outcome and other one is days of hospitalization. Irrational prescribing directly affects these two parameters. In our study, out of 400 patients, majority i.e.30.75\% (323) patients were discharged. Significant number i.e. $13.50 \%$ (54) percentage of patients were taken discharge against medical advice (DAMA), 3\% (12) were absconded while treatment is going on. Also, 2.25\% (9) patients were taken discharge on request (DOR). Due to Irrational prescribing patients loses faith on doctor and his/her treatment. Which in turn increase the number of patients taking DAMA or DOR. As in our case almost $15.75 \%$ patients did the same thing.

Overall impact of irrational prescribing is increased days of hospitalization. Also polypharmacy and increased days of hospitalization goes hand in hand. In our study around $39.75 \%$ prescriptions were having polypharmacy. Polypharmacy is associated with increased hospital admissions. Similar results were shown in the study done by Payne et al. ${ }^{19}$ Irrational prescribing can also lead to many adverse effects which in turn increase the number of days of hospitalization. ${ }^{20}$

With the help of Ronal Neville G criteria, we also found out prescription errors. These errors were divided into four categories according to its severity impact into Class A, B, $\mathrm{C}$ and type D. out of 400 prescriptions majority of prescriptions i.e. $73 \%$ (292) were having one of the type of error. Around $27 \%$ ( 108) prescriptions were not having any sort of prescription error. Further analysis showed that class D type of errors contribute maximum to the prescription errors i.e. $42.75 \%$. These errors are mainly due to illegible handwriting, wrong dosage form and spelling mistakes which can be easily avoided. Class $\mathrm{C}$ contributes $24 \%$ to these errors. Which are having minor impact and can be corrected by person who will dispense it. For example, wrong pack size of dermatological preparation. Class B errors contributes major impact on health.

In the study conducted by Mohan et al, they analyzed and classified the prescription errors according to Neville et al. They found that out of total 1000 prescription, $65 \%$ have one or more errors. Total numbers of errors were 1012. All types of error except type A were observed in this study. Type B errors and type $\mathrm{C}$ were found to be in $22.4 \%$ and $9.7 \%$ prescription. Most common type of error was type D and was found in $69.1 \%$ prescriptions. $^{21}$

Before dispensing such medicines, it is necessary to contact the concern prescriber. This is to confirm right drug and its appropriate dosage form. Person dispensing it cannot take his or her own decision. For example, completely illegible script, forget to write dosage form in front of phenytion. Very hazardous class A type of prescription error contributes $3.25 \%$ (13). These errors are potentially hazardous to health. It includes prescribing contraindicated medicines, confusion between writing moreover similar drugs (such as between chlorpromazine and chlorpropamide) and writing wrong doses with wrong units. Especially cardiac drugs where it's very much important to write right dose with right unit. Using or writing gram instead of milligram can create huge problem and can be life threatening too.

\section{Limitations}

While evaluating we did not categories prescriber according to their designation i.e. junior resident/ senior resident/lecturer. Study was limited to medicine ward only. We are planning to re-study the above-mentioned parameters after an intervention. The intervention will comprise of prescriber sensitization through seminars and CMEs. We also plan to increase awareness among prescribers by handouts and personal discussions.

\section{CONCLUSION}

The present study showed that according to WHO drug prescribing indicators the practices were trending towards irrational prescribing. The average number of drugs per prescription was significantly high which clearly indicates polypharmacy. Use of generic drugs and drugs from NELM are much lower than WHO standards. Use of injectable drugs is high generating biomedical waste, and increasing the cost. Many prescriptions were having improper dose which needs rectification. Also, large number of prescription errors were simply because of spelling mistakes. These errors can be easily avoided by creating awareness about it among prescriber. For the same regular audit and evaluation of prescription has to be done. Also, sensitization of prescriber about these errors and irrational prescribing, new treatment guidelines through seminar, presentations and CME has to be done on regular basis.

\section{ACKNOWLEDGEMENTS}

The authors are thankful to the staff of medical record section for cooperation throughout the study. Authors are also thankful to the Dean for permitting access to medical records. They would take this opportunity to than the Department of Medicine, who boldly came forward to get their prescriptions scrutinised. 
Funding: No funding sources

Conflict of interest: None declared

Ethical approval: The study was approved by the Institutional Ethics Committee

\section{REFERENCES}

1. World health organization. introduction to drug utilization research. OSLO: world health organization; 2003.

2. Who, policy perspective on medicines; promoting rational use of medicines; core components, Geneva; 2002.

3. Kumar SBP. A study on drug use pattern using who prescribing indicators in in-patients of medicine department in a rural tertiary care teaching hospital. Indo American Journal of Pham Research. 2015;5(05):2041-6.

4. Jhaveri BN, Patel TK, Barvaliya MJ, Tripathi CB. drug utilization pattern and pharmacoeconomics analysis in geriatric medical in-patients of a tertiary care hospital of india. journal of pharmacology and pharmacotherapeutics. 2014 Jan-Mar;5(1):15-20.

5. Hogerzeil HV, Bimo, Ross-Degnan D, Laing RO, Ofori-Adjei D, Santoso B, et al. Field tests for rational drug use in twelve developing countries, Lancet. 1993;342(8884):1408-10.

6. Neville RG, Robertson FI, Livingstone SU, Crombie IK. A classification of prescription errors. JR Coll Gen Pract. 1989 Mar 1;39(320):110-2.

7. World health organization. how to investigate drug use in health facilities selected drug use indicators. Geneva, Switzerland: WHO; 1993:25-31.

8. Kuijpers MA, Van Marum RJ, Egberts AC, Jansen PA. relationship between polypharmacy and under prescribing. British Journal of Clinical Pharmacology. 2008 Jan;65(1):130-3.

9. Pathak A, Gupta VK, Maurya A, Kumar A, Singh A. assessment of drug prescribing pattern using who indicators in hospitalized patients at a tertiary care teaching hospital in rural area of India. Int J Basic Clin Pharmacol. 2016;5:651-5.

10. Meena N, Rita S, Sania MKH, Gunaseelan V, Thangkhiew B. drug prescription pattern in a tertiary health centre in Imphal: a cross sectional study. Int J Pharm B Sci. 2013;4(4):838-42.

11. Medical council of India. notification[internet]. New Delhi:MCI; 2017April17. Available at: www.mciindia.org/circulars/Public-Notice-GenericDrugs-21.04.2017.

12. Gopalakrishnan S, Ganeshkumar P, Katta A. assessment of prescribing practices among urban and rural general practitioners in Tamil Nadu. Indian $\mathbf{J}$ Pharmacol. 2013;45:252-7.

13. National centre for disease control directorate general of health services ministry of health and family welfare government of India. National treatment guidelines for antimicrobial use in infectious diseases. version 1: GOI; 2016. Available at: pbhealth.gov.in/AMR_guideline7001495889.

14. Maselle AY, Mashalla YJ, Kayombo EJ, Mwaiselage JD, Mwamba NE, Kaniki I. reducing therapeutic injection overuse through patients-prescribers interaction group discussions in Kinondoni District, Dar Es Salaam, Tanzania. Tanzan J Health Res. 2011;13:87-92.

15. Tripathi KD. Essential of medical pharmacology. 7th edition. New Delhi: Jaypee Brothers Medical publishers(P) limited; 2014.

16. Vinnakota NR, Krishna V, Viswanath V, Ahmed Z, Shaik KS, Boppana NK. assessment of knowledge, attitude, and practices on fixed dose combinations among postgraduate dental students. Journal of International Society of Preventive and Community Dentistry. 2016 Dec 1;6(9):243.

17. Rahmawati F, Pramantara IP, Rohmah W, Sulaiman SA. polypharmacy and unnecessary drug therapy on geriatric hospitalized patients in Yogyakarta hospitals, Indonesia. Int J Pharm Pharm Sci. 2009 nov;1(1):6-11.

18. Lee G. Pentazocine potentially hazardous in acute myocardial infarction. Inpharma. 1976:14.

19. Payne RA, Abel GA, Avery AJ, Mercer SW, Roland Mo. is polypharmacy always hazardous? a retrospective cohort analysis using linked electronic health records from primary and secondary care. british journal of clinical pharmacology. 2014 Jun 1;77(6):1073-82.

20. Nobili A, Licata G, Salerno F, Pasina L, Tettamanti M, Franchi C, et al. polypharmacy, length of hospital stay, and in-hospital mortality among elderly patients in internal medicine wards. The reposi study. European journal of clinical pharmacology. 2011 May 1;67(5):507-19.

21. Prafull M, Sharma AK, Panwar SS. Identification and quantification of prescription errors. medical journal armed forces India 70. 2014 Apr:149-153.

Cite this article as: Bachewar NP, Choudhari SR, Dudhgaonkar S. Assessment of prescription pattern using WHO drug prescribing indicators in medicine wards of a tertiary care teaching hospital: a retrospective observational study. Int J Basic Clin Pharmacol 2017;6:2070-7. 